\title{
Use of levosimendan in acute and advanced heart failure: short review on available real-world data
}

This article was published in the following Dove Press journal:

Therapeutics and Clinical Risk Management

\section{Eugene Pashkovetsky Chhaya Aggarwal Gupta Wilbert S Aronow}

Division of Cardiology, Department of Medicine, Westchester Medical Center and New York Medical College, Valhalla, NY 10595, USA
Correspondence: Wilbert S Aronow Cardiology Research, Westchester Medical Center and New York Medical College, 100 Woods Road, Valhalla, NY 10595, USA

$\mathrm{Tel}+|9| 449353||$

Fax + I 9142356274

Email wsaronow@aol.com

\begin{abstract}
Published data have shown potential advantages of levosimendan in the management of acute decompensated heart failure and advanced heart failure when standard medical therapies threaten hemodynamics and organ perfusion are unable to alleviate clinical symptoms. Levosimendan distinguishes itself from other catecholaminergic inotropes by its three mechanisms of action: positive inotropy, vasodilation, and cardioprotection. In addition, its pharmacokinetics allow for a longer duration of action from the metabolite OR1896 allowing for further cardiovascular therapeutic effects for several days, even after discontinuation of the parent drug.
\end{abstract}

Keywords: levosimendan, heart failure, inotropic therapy

\section{Introduction}

Heart failure is a chronic clinical disease that may result from disorders of the pericardium, myocardium, endocardium, heart valves, or certain metabolic abnormalities. It is usually associated with a series of functional and structural left ventricular abnormalities that may range from patients with normal left ventricular dimensions and preserved ejection fraction (classically reported as $\geq 50 \%$ ) to those with a significantly dilated left ventricular cavity, decline in ventricular filling, and/ or reduced ejection fraction (classically reported as $<40 \%$ ). ${ }^{1,2}$ Patients commonly present with limitations in exercise tolerance, fluid retention, pulmonary and/or splanchnic congestion, and dependent edema. ${ }^{1}$

The American College of Cardiology-American Heart Association task force classified the progression of heart failure syndrome into four stages. Asymptomatic patients with cardiovascular risk factors but without any structural heart disease are defined as stage A. Stage B is defined as patients without heart-failure symptoms but who have developed structural heart disease. As the heart fails, the onset of overt heartfailure symptoms in the presence of structural heart disease is defined as stage $\mathrm{C}$. Those patients who unfortunately continue to worsen and remain refractory to guidelinedirected medical therapy are termed advanced heart failure - stage D. The New York Heart Association (NYHA) functional classification (I-IV), on the other hand, is used to describe severity of symptoms, from class I patients, who have no limitations of physical activity to class IV patients, who have heart-failure symptoms at rest and experience a deterioration in their quality of life. ${ }^{1-3}$

Though there is a well-defined relationship between survival and severity of symptoms, there is a modest correlation between left ventricular function and severity of symptoms. ${ }^{4}$ Therefore, those patients with trivial symptoms may still 
experience worsening clinical status that requires frequent hospitalizations and even death. ${ }^{4-6}$

Consequently, the term "advanced heart failure" is used to differentiate patients with severe symptoms, recurrent decompensation, and marked severe cardiac dysfunction. ${ }^{7}$ In advanced heart failure, patients become intolerant to goal-directed medical therapy, which includes diuretics, $\beta$ adrenergic blockers, angiotensin-converting enzyme inhibitors, angiotensin-receptor blockers, angiotensin receptorneprilysin inhibitors, mineralocorticoid-receptor antagonists, and ivabradine. ${ }^{2}$ While the use of catecholaminergic inotropes has been described to improve NYHA functional class, as well as having favorable effects on hemodynamics, for clinically low-output patients, it has not demonstrated an impact on survival. ${ }^{8}$ Additional interventions must be considered. Patients with advanced heart failure ultimately fall into three different scenarios. These pathways include definitive intervention through heart transplantation, surgical implantation of a left ventricular assist device (as a means of being a bridge to heart transplantation, destination therapy, or a bridge to a decision), or palliative care pathway. The primary goals of undergoing an intervention include hemodynamic stabilization and preservation of healthrelated quality of life. For palliative measures, an important goal is to prevent heart-failure hospitalizations, keep the patient comfortable, and to decrease worsened mortality. ${ }^{9-11}$

Rapid onset of decompensated symptoms and/or signs of heart failure are defined as acute heart failure. This may present as a new, undiagnosed syndrome or as a decompensation of chronic heart failure. Acute heart failure can present without known precipitating factors, be directly due to a primary cardiac dysfunction, such as myocardium, endocardium, and heart-valve abnormalities, or from a combination of causes, such as dietary indiscretion, nonadherence to medications, arrhythmia, infection, or metabolic abnormalities. ${ }^{2}$

Excerpts from evidence-based guidelines provide a structure within which the potential role of levosimendan can be applied in the management of acute and advanced heart failure. ${ }^{12}$ Levosimendan is a calcium sensitizer and potassiumchannel opener that has been proposed as a safer positive inotropic agent with peripheral vasodilator properties compared with traditional agents in acute and advanced heart failure. There have been multiple meta-analyses describing the hemodynamic properties of levosimendan in heart failure, which include dose-dependent increases in cardiac output and stroke volume with reductions in pulmonary capillary- wedge pressure, mean right atrial pressure, and pulmonary artery pressure. ${ }^{13,14}$ These valuable alterations in patients' hemodynamic profiles potentially allow for the resolution of symptoms of acute decompensated heart failure ${ }^{15}$ and reduction in the likelihood of hospitalization. ${ }^{16}$ It has also been stated to be the only inotrope associated with improved survival, which adds to the uniqueness of this medication among other inotropic agents. ${ }^{17,18}$ This focused review examines the use of levosimendan in acute and advanced heart failure.

\section{Levosimanden: mechanism of action}

Levosimendan is an inotropic drug that has three major mechanisms of action: positive inotropy, vasodilation, and cardiac cytoprotection. ${ }^{15}$ The first major mechanism of action of levosimendan is its interaction with cardiac troponin $\mathrm{C}$ to form the basis of its $\mathrm{Ca}_{2}{ }^{+}$-sensitizing mechanism. ${ }^{19}$ The binding of the drug to troponin $\mathrm{C}$ increases the sensitivity of troponin $\mathrm{C}$ fibers to ionic free calcium, which in turn helps protract the molecular interaction between troponin $\mathrm{C}$ and troponin $\mathrm{I}$, thus increasing cardiac contractility without increasing ionic free calcium. ${ }^{20}$ This is a distinctive feature of levosimendan compared with all other inotropic agents, which increase the concentration of ionic free calcium in cardiomyocytes, exposing them to lethal concentrations of ionic calcium. Elevated intracellular ionic calcium has been associated with cardiac remodeling, arrhythmia, and increase in oxygen consumption. ${ }^{12,21,22}$ Even with its direct effects of increasing myocardial contractility and enhancing rapid ventricular filling, levosimendan does not affect left ventricular relaxation. ${ }^{23}$

The second mechanism of action of levosimendan is its vasodilatory properties. ${ }^{24}$ The drug is capable of opening ATP-dependent potassium channels in vascular smooth muscles, which results in dilatation of arteries in coronary, peripheral, and pulmonary circulation while causing venodilation of the portal and saphenous systems, thus causing a reduction in right ventricular preload and afterload. ${ }^{24-27}$ The third mechanism of action of the drug is its cytoprotective properties. Experimental studies have suggested that levosimendan's ability to open cardiac mitochondrial ATP-sensitive $\mathrm{K}^{+}$channels can reduce production of free radicals within the cells. ${ }^{15}$ This in turn provides protection against stressful conditions to the cell and reduces cell destruction and stimulation of production of inflammatory response markers. ${ }^{28}$ Cardioprotection during acute and chronic heart failure via reduction in myocardial inflammation, remodeling, ischemia-reperfusion injury, and 
myocyte apoptosis has also been recognized with the use of levosimendan and/or its active metabolite OR1896. ${ }^{29-32}$ This effect was not only observed in myocardial cells but also in brain cells. ${ }^{33}$

\section{Pharmacokinetics}

Levosimendan is set apart by its pharmacokinetics. During the metabolism of levosimendan, a small portion of the drug $(5 \%)$ is converted via a reduction-acetylation pathway in the large intestines to the metabolite OR1855 and then active metabolite OR1896 in the liver. ${ }^{34}$ Metabolite OR1896 has comparable hemodynamic and pharmacologic effects to levosimendan, but unlike the parent drug, the elimination half-life is greatly extended to about 80 hours from 1 hour, thus further providing its cardiovascular therapeutic effects for several days, even after discontinuation of a 24 hour infusion of the parent drug. ${ }^{35}$ It is also important to note that the pharmacokinetics of levosimendan remain constant in patients with hepatic and renal impairment. ${ }^{12,36}$

\section{Administration}

Infusion is often started at a dose of $0.1 \mathrm{mg} / \mathrm{kg} / \mathrm{min}$ and titrated to $0.2 \mathrm{mg} / \mathrm{kg} / \mathrm{min}$ as long as systolic blood pressure remains stable after the first $2-3$ hours. The recommended interval of infusion in acute heart failure is 24 hours. Initial bolus of levosimendan is not usually given, in order to prevent risk of hypotension in patients who have systolic blood pressure $<100 \mathrm{mmHg}$ or diastolic blood pressure $<60 \mathrm{mmHg}{ }^{2}$

\section{Hemodynamic effects}

Use of levosimendan results in dose-dependent increases in cardiac output, stroke volume, and decreases in mean pulmonary artery pressure, pulmonary capillary-wedge pressure, and systemic vascular resistance. ${ }^{14}$ The increase in cardiac output induced by the infusion of this drug is similar to the effect achieved with a comparable dose of dobutamine, but a decline in right atrial pressure and pulmonary capillary-wedge pressure is superior. ${ }^{2,37}$

\section{Adverse effects}

Levosimendan has been well tolerated in patients with acute left heart failure. ${ }^{27}$ Common adverse effects reported are hypotension, headache, and dizziness secondary to the vasodilating properties. ${ }^{15}$ Increased incidence of atrial fibrillation has also been associated with infusion of levosimendan compared with both dobutamine and placebo. $^{27,38}$

\section{Levosimendan in acute heart failure}

Levosimendan provides sustained relief of symptoms for patients who present with acute decompensated heart failure. ${ }^{39}$ In the REVIVE II trial $(n=600)$, patients with decompensated heart failure, mean left ventricular ejection fraction $\leq 23 \%$, and dyspnea at rest who were on intravenous diuretics were randomized in a double-blind manner to treatment with intravenous levosimendan $(6-12 \mu \mathrm{g} / \mathrm{kg}$ bolus followed by $0.1-0.2 \mu \mathrm{g} / \mathrm{kg} / \mathrm{min}$ infusion for 24 hours), in addition to standard therapy $(\mathrm{n}=299)$ or placebo $(n=301)$. The primary end point of change in clinical course through 5 days showed greater improvements (by $33 \%$ ) in the levosimendan group compared with placebo group. Also, patients requiring rescue therapy were fewer in the levosimendan group ( $15 \%$ vs $26 \%$ ), as was the case for worsening dyspnea or tachypnea ( $7 \%$ vs $12 \%)$ and unresponsive symptoms ( $6 \%$ vs $10 \%)$. Hospital length of stay was shorter in the levosimendan group ( 7.0 days vs 8.9 days, $P=0.006$ ). Adverse events in this clinical trial showed that hypotension and atrial fibrillation occurred more frequently in the levosimendan group. ${ }^{40}$

In the RUSSLAN trial $(n=504)$, patients who were within 5 days of an acute myocardial infarction, evidence of left ventricular failure on chest X-ray, and in clinical need of inotropic therapy were randomized to placebo or one of four doses of levosimendan: $6 \mu \mathrm{g} / \mathrm{kg}$ loading dose + $0.1 \mu \mathrm{g} / \mathrm{kg} / \mathrm{min}$ infusion, $12 \mu \mathrm{g} / \mathrm{kg}$ loading dose $+0.2 \mu \mathrm{g} /$ $\mathrm{kg} / \mathrm{min}$ infusion, $24 \mu \mathrm{g} / \mathrm{kg}$ loading dose $+0.2 \mu \mathrm{g} / \mathrm{kg} / \mathrm{min}$ infusion, or $24 \mu \mathrm{g} / \mathrm{kg}$ loading dose $+0.4 \mu \mathrm{g} / \mathrm{kg} / \mathrm{min}$ infusion. Though invasive hemodynamic monitoring was not performed, those patients that had persistent hypotension or continued decompensated heart failure during infusion of levosimendan were permitted to receive intravenous dopamine. A lower incidence of death or worsening heart failure at 24 hours was reported with levosimendan infusion versus placebo ( $4 \%$ vs $8.8 \%, P=0.04$ ). At 14 and 180 days, lower mortality was also associated with levosimendan infusion versus placebo ( $11.7 \%$ vs $19.6 \%, P=0.03$ and $22.6 \%$ vs $31.4 \%, P=0.05$, respectively). It was found that the highest dose of levosimendan was associated with increased incidence of hypotension or cardiac ischemia (19\% with the $24 \mu \mathrm{g} / \mathrm{kg}$ loading dose $+0.4 \mu \mathrm{g} / \mathrm{kg} / \mathrm{min}$ infusion vs $10.8 \%$ with placebo, $P=0.05){ }^{41}$

The SURVIVE trial $(\mathrm{n}=1,327)$ compared the effects of levosimendan (infused at rates of $0.1-0.2 \mu \mathrm{g} / \mathrm{kg} / \mathrm{min}$ for 
24 hours) to dobutamine on mortality in patients with severe systolic heart failure. Though no significant difference was demonstrated in the primary end point of 180day mortality between levosimendan and dobutamine, the survival rate in the levosimendan group was significantly higher in the subgroup of patients with a history of heart failure (1,171 patients, $88.2 \%$ of the study population), with 19 fewer deaths up to 31 days $(P=0.05){ }^{42}$

Available data regarding the use of levosimendan in refractory cardiogenic shock patients undergoing peripheral venoarterial extracorporeal membrane oxygenation (VA-ECMO) remains limited. In a retrospective single-center study $(n=150)$ where 38 propensity-matched patients were evaluated in a levosimendan group (continuous infusion at a dose of 0.2 $\mu \mathrm{g} / \mathrm{kg} / \mathrm{min}$ for 24 hours) and 65 in a nonlevosimendan group, levosimendan was administered $3.2 \pm 2.8$ days after VAECMO cannulation. In patients treated with levosimendan, left ventricular ejection fraction increased from $21.5 \% \pm 9.1 \%$ to $30.7 \% \pm 13.5 \%(P<0.0001)$ Of 150 patients, 103 were weaned from VA-ECMO (68.7\%): $42(82.4 \%)$ in the levosimendan group versus $61(61.6 \%)$ in the nonlevosimendan group $(P=0.01)$. Kaplan-Meier survival curves showed that survival at 30 days was $78.4 \%$ in the levosimendan group and $49.5 \%$ in the nonlevosimendan group $(P=0.02)$, but after propensity score-matching analysis, the difference in 30-day mortality between the two groups was not significant (HR $0.55,95 \%$ CI $0.27-1.10 ; P=0.09) .{ }^{43}$ Also, given levosimendan's cytoprotective effects on endothelium function, ${ }^{15,27,44}$ it was reported in a observational study that levosimendan led to significant improvement in endothelial function and cardiac index in cardiogenic shock patients with low ejection on VAECMO. $^{45}$

\section{Levosimendan and advanced heart failure}

There is evidence for clinical benefit of survival and reduced hospitalizations with intermittent use of levosimendan, as well as continuing symptomatic improvement or palliation in patients with advanced heart failure. ${ }^{3,46}$ This further encouraged the movement for a series of larger randomized trials. The LevoRep study was a prospective, randomized, double-blind, placebo-controlled, multicenter, parallel-group trial of pulsed infusions of levosimendan in 120 outpatients with advanced heart failure (ejection fraction $\leq 35 \%$, NYHA class III-IV). Levosimendan $(0.2 \mu \mathrm{g} / \mathrm{kg} / \mathrm{min})$ or placebo was given for 6 hours in 2-week intervals over a 6-week treatment period, in addition to standard-care therapy. Follow-up visits were scheduled at 2 and 18 weeks after the treatment period. The primary outcome was the proportion of patients with $\geq 20 \%$ improvement in the 6-minute walk test and $\geq 15 \%$ score increase on the Kansas City Cardiomyopathy Questionnaire at the end of the 24-week study period. The primary end point was reached in $19 \%$ of patients receiving levosimendan and $15.8 \%$ of those receiving placebo (OR $1.25,95 \%$ CI $0.44-3.59 ; P=0.81)$. These results showed that pulsed infusions of levosimendan did not improve functional capacity or quality of life significantly compared with placebo in patients with advanced heart failure. Pulsed levosimendan infusions were associated with a reduction in systolic blood pressure compared to placebo. Overall, the frequency of side effects was low $(<3 \%)$ in both groups with respect to tachycardia, new-onset atrial fibrillation, and unsustained ventricular tachycardia. ${ }^{47}$

The LION-HEART trial was a multicenter, doubleblind, randomized, parallel-group, placebo-controlled trial that looked at the efficacy and safety of intravenous administration of intermittent doses of levosimendan in outpatients with advanced heart failure. A total of 69 patients were randomly assigned at a 2:1 ratio to levosimendan $(n=48)$ or placebo $(n=21)$ treatment by a 6 hour intravenous infusion $(0.2 \mu \mathrm{g} / \mathrm{kg} / \mathrm{min}$ without bolus) every 2 weeks for 12 weeks. The primary end point was change in serum concentrations of $\mathrm{N}$-terminal pro-brain natriuretic peptide (NT-proBNP) from baseline. The area under the curve $(\mathrm{pg} \cdot$ day/mL) for NTproBNP levels in patients receiving levosimendan was significantly lower than for the placebo group $\left(344 \times 10^{3}\right.$ $\left[95 \%\right.$ CCI $\left.283 \times 10^{3}-404 \times 10^{3}\right]$ vs $535 \times 10^{3} \quad[95 \%$ CI $\left.\left.443 \times 10^{3}-626 \times 10^{3}\right], \quad P=0.003\right)$. Secondary end points looked at safety, clinical events, and health-related quality of life. The levosimendan group had a reduction in the rate of heart-failure hospitalization (HR 0.25, 95\% CI 0.11-0.56; $P=0.001$ ) and were less likely to experience a clinically significant decline in health-related quality of life over time $(P=0.022)$. In terms of adverse effects, the levosimendan group needed dose reductions due to hypotension (systolic blood pressure $<80 \mathrm{mmHg}$; levosimendan $15 \%$, placebo $9 \%$ ), but this distinction did not reach statistical significance. $^{48}$

The LAICA trial was also a multicenter, prospective, randomized, double-blind, placebo-controlled, parallelgroup trial that assessed the efficacy and safety of longterm intermittent infusion of levosimendan. A total of 97 patients who had advanced heart failure with at least one 
hospital admission for acute decompensation or heartfailure worsening within 6 months were randomized (levosimendan 70 and placebo 27) to receive 24-hour infusions every 30 days, in addition to optimal standard heart-failure therapy. The primary end point was the incidence of hospitalization for acute decompensated heart failure in patients with advanced heart failure.

Secondary end points were cumulative incidence of hospitalization for acute decompensated heart failure and/ or mortality at 30 days and after 3, 6, and 12 months. The study did not demonstrate statistical significance for the primary end point, but the results did support levosimendan in terms of fewer admissions for acute decompensated heart failure and in terms of lower mortality rates (levosimendan $6.6 \%$; placebo $22.2 \%$; $[P=0.0439$ by log-rank test). ${ }^{3,49}$ These three major randomized clinical trials collectively demonstrate reduction in NT-pro-BNP levels and trends in reductions in heart-failure readmissions, as well as heart failure-related mortality from intermittent infusion of levosimendan in advanced heart failure. ${ }^{47,50}$

\section{Levosimendan and renal perfusion}

There is a well-recognized association between failing renal function and worsening of prognosis in acute decompensated heart failure. It is important to note that an increase in central venous pressures can decrease the glomerular filtration rate, as the kidneys are encapsulated organs and increase in their pressure can cause end-organ damage. Increasing cardiac output, decreasing central venous pressure, and maintaining renal perfusion pressure are important targets. ${ }^{12,50}$ Levosimendan has been actively reviewed in several trials for its effects on renal function in heart failure. The LIDO study found that compared to dobutamine, infusion of levosimendan was associated with significant reduction in serum creatinine $(0.011 \mathrm{mg} /$ $\mathrm{dL}, P=0.03$ ) in the short term. ${ }^{51}$ Similar conclusions were found versus dobutamine by Yilmaz et al. ${ }^{52}$ However, Lannemyr et al conducted a single-center, randomized, double-blind study where 33 patients with chronic heart failure (left ventricular ejection fraction <40\%) and impaired renal function (glomerular filtration rate $<80 \mathrm{~mL} / \mathrm{min} / 1.73 \mathrm{~m}^{2}$ ) were randomized to receive either levosimendan (loading dose $12 \mu \mathrm{g} / \mathrm{kg}+0.1 \mu \mathrm{g} / \mathrm{kg} / \mathrm{min}$ ) or dobutamine $(7.5 \mu \mathrm{g} / \mathrm{kg}$ per minute) in a $1: 1$ fashion for 75 minutes. The study measured each patient's systemic hemodynamics via a pulmonary artery catheter, renal plasma flow, and filtration fraction by renal extraction of chromium EDTA using a renal vein catheter. Results showed that while both groups had similar increases in renal blood flow, the glomerular filtration rate increased by $22 \%$ in the levosimendan group, but remained unchanged in the dobutamine group $(P=0.012) .{ }^{53}$ Zemljic et al published findings of long-term impact of levosimendan on renal function in patients on waiting lists for transplantation. Results showed that at 3 months after infusion, there had been a decrease in serum creatinine and an increase in creatinine clearance in the levosimendan group, but not in the control (difference in serum creatinine $1.60 \pm 0.26 \mathrm{mg}$ / $\mathrm{dL}$ in levosimendan group versus $1.90 \pm 0.14 \mathrm{mg} / \mathrm{dL}$ in control, $P=0.005)$ and creatinine clearance $(53.6 \pm 8.6 \mathrm{~mL} /$ $\mathrm{min}$ in levosimendan group versus $44.0 \pm 3.3 \mathrm{~mL} / \mathrm{min}$ in control, $P=0.005) .{ }^{54}$ It is acceptable to conclude that levosimendan appears in these data to be indicated for shortterm management of cardiorenal syndrome in acute decompensated heart failure.

\section{Levosimendan and pulmonary hypertension}

Pulmonary hypertension $(\mathrm{PH})$ is defined as an increased mean pulmonary arterial pressure $\geq 25 \mathrm{mmHg}$. The World Health Organization has classified PH into five clinical groups: pulmonary arterial hypertension (group 1), $\mathrm{PH}$ due to left heart disease (group 2), PH due to lung diseases and/or hypoxemia (group 3), $\mathrm{PH}$ due to chronic thromboembolism (group 4), and PH with unclear and/or multifactorial mechanisms (group 5). ${ }^{55}$

Levosimendan has been proposed in the management of $\mathrm{PH}$ and right heart failure, given its pharmacodynamic profile of reducing both PVR and pulmonary capillary-wedge pressure. ${ }^{27}$ Jiang et al published findings of a prospective open-label study of 45 hospitalized patients with pulmonary arterial hypertension treated with levosimendan. Levosimendan improved seven of $13 \mathrm{PH}$ patients with WHO functional class IV by one class $(P=0.008)$, Borg dyspnea score, 6-minute walk test, biochemical markers $(P<0.001)$, and echocardiographic parameters of RV function. ${ }^{56}$ Similar results were published by Martynuik et al in a prospective single-arm study of nine patients with pulmonary arterial hypertension functional class III and IV and severe right ventricular failure.Levosimendan infusion for 24 hours resulted in substantial reductions in pulmonary artery systolic pressure, mean pulmonary artery pressure, mean right atrial pressure, pulmonary vascular resistance, and NT-proBNP levels while increasing exercise tolerance. At 12 weeks after discontinuation of levosimendan, hemodynamic parameters remained improved, as did functional class. ${ }^{57}$ 
$\mathrm{PH}$ related to left heart disease signifies the most common type of PH. Given levosimendan's ability to decrease pulmonary arterial pressure and improve right ventricular function and clinical symptoms, it may seem promising in the management of PH due to left heart disease. ${ }^{27}$ Poelzl et al studied 18 patients with acute heart failure (left ventricular ejection fraction $\leq 30 \%$ ), cardiac index $\leq 2.5 \mathrm{~L} / \mathrm{min} / \mathrm{m}^{2}$, right atrial pressure $\geq 10 \mathrm{mmHg}$, pulmonary capillary-wedge pressure $\geq 15 \mathrm{mmHg}$ ) with predominantly right ventricular failure who received 24 hours' levosimendan found pulmonary capillary-wedge pressure and systemic vascular resistance decreased, whereas decreases in mean pulmonary artery pressure and pulmonary vascular resistance were not significant. ${ }^{58}$ In a study by Yilmaz et al, 40 patients with acute decompensated systolic heart failure and right ventricular dysfunction were randomized to open-label levosimendan or dobutamine. Both treatment arms demonstrated an improvement in right ventricular ejection fraction and a decrease in systolic pulmonary arterial pressure. Interestingly, the levosimendan group showed an improvement in both serum creatinine and 24-hour urine output compared with the dobutamine group. ${ }^{59}$ Mishra et al published a randomized clinical trial comparing effects of levosimendan to milrinone in patients with $\mathrm{PH}$ and left ventricular dysfunction undergoing valve replacement. Levosimendan was found to be analogous to milrinone in improving biventricular function, reducing mean pulmonary arterial pressure, and pulmonary vascular resistance, yet levosimendan resulted in an increase in heart rate and cardiac index, decrease in systemic vascular resistance index, and increased necessity for norepinephrine. ${ }^{60}$

\section{Conclusion}

Published data have shown potential advantages of levosimendan in the management of acute decompensated heart failure and advanced heart failure when standard medical therapies threaten hemodynamics and organ perfusion and are unable to alleviate clinical symptoms. The LION-HEART and LAICA trials of intermittent infusions of levosimendan demonstrated several clinical benefits, such as improved cardiac biomarkers, symptoms, quality of life, rehospitalization rates, and reduction of heart failure-related mortality. Levosimendan distinguishes itself from other catecholaminergic inotropes by its three mechanisms of action: positive inotropy, vasodilation, and cardioprotection. In addition, its pharmacokinetics allow for a longer duration of action from metabolite OR1896, allowing for further therapeutic cardiovascular effects for several days, even after discontinuation of the parent drug. Data supporting the use of levosimendan show that the medication is generally well tolerated and has encouraging future perspectives in the management of acute and advanced heart failure.

\section{Disclosure}

The authors report no conflicts of interest in this work.

\section{References}

1. Yancy CW, Jessup M, Bozkurt B, et al. ACCF/AHA guideline for the management of heart failure. Circulation. 2013;128(16). doi:10.1161/ CIR.0b013e31829e 8776

2. Ponikowski P, Voors AA, Anker SD, et al. ESC guidelines for the diagnosis and treatment of acute and chronic heart failure. Eur J Heart Fail. 2016;18(8):891-975. doi:10.1002/ejhf.592

3. Fedele F, Kivikko M, Tschöpe C, et al. Repetitive levosimendan treatment in the management of advanced heart failure. Eur Hear J Suppl. 2018. doi:10.1093/eurheartj/suy040

4. McMurray JJV. Systolic heart failure. N Engl J Med. 2010;362 (3):228-238. doi:10.1056/NEJMcp0909392

5. Chen J, Normand S-LT, Wang Y, Krumholz HM. National and regional trends in heart failure hospitalization and mortality rates for medicare beneficiaries, 1998-2008. Jama. 2011;306 (15):1669-1678. doi:10.1001/jama.2011.1474

6. Redfield MM, Jacobsen SJ, Burnett JC, Mahoney DW, Bailey KR, Rodeheffer RJ. Burden of systolic and diastolic ventricular dysfunction in the community: appreciating the scope of the heart failure epidemic. JAMA. 2003;289(2):194-202. Available from: http://www. ncbi.nlm.nih.gov/pubmed/12517230. Accessed February 21, 2019.

7. Metra M, Ponikowski P, Dickstein K, et al. Advanced chronic heart failure: a position statement from the Study Group on Advanced Heart Failure of the Heart Failure Association of the European Society of Cardiology. Eur J Heart Fail. 2007;9(6-7):684-694. doi:10.1016/j.ejheart.2007.04.003

8. Nizamic T, Murad MH, Allen LA, et al. Ambulatory inotrope infusions in advanced heart failure. JACC Hear Fail. 2018;6(9):757-767. doi:10.1016/j.jchf.2018.03.019

9. Solomon SD, Dobson J, Pocock S, et al. Influence of nonfatal hospitalization for heart failure on subsequent mortality in patients with chronic heart failure. Circulation. 2007;116(13):1482-1487. doi:10.1161/CIRCULATIONAHA.107.696906

10. Setoguchi S, Stevenson LW, Schneeweiss S. Repeated hospitalizations predict mortality in the community population with heart failure. Am Heart J. 2007;154(2):260-266. doi:10.1016/j. ahj.2007.01.041

11. Nieminen MS, Altenberger J, Ben-Gal T, et al. Repetitive use of levosimendan for treatment of chronic advanced heart failure: clinical evidence, practical considerations, and perspectives: an expert panel consensus. Int $J$ Cardiol. 2014;174(2):360-367. doi:10.1016/j. ijcard.2014.04.111

12. Husedzinovic I, Husedzinovic S, Milanovic R. Levosimendan in acute heart failure. Signa Vitae - A J Intensive Care Emerg Med. 2017. doi: $10.22514 / \mathrm{sv} 31.022008 .3$

13. García-González MJ, Jorge-Pérez P, Jiménez-Sosa A, Acea AB, Lacalzada Almeida JB, Ferrer Hita JJ. Levosimendan improves hemodynamic status in critically ill patients with severe aortic stenosis and left ventricular dysfunction: an interventional study. Cardiovasc Ther. 2015;33(4):193-199. doi:10.1111/1755-5922.1 2132

14. Nieminen MS, Akkila J, Hasenfuss G, et al. Heart failure hemodynamic and neurohumoral effects of continuous infusion of levosimendan in patients with congestive heart failure. $\mathrm{J} \mathrm{Am}$ Coll cardiol. 36;2000. doi:10.1016/S0735-1097(00)00961-X 
15. De Hert SG, Wikström BG, Meyer S, et al. Levosimendan: molecular mechanisms and clinical implications. Int $J$ Cardiol. 2011. doi:10.1016/j.ijcard.2011.07.022

16. Jia Z, Guo M, Zhang Y-Q, Liang H-Q, Zhang L-Y, Song Y. Efficacy of intravenous levosimendan in patients with heart failure complicated by acute myocardial infarction. Cardiology. 2014;128 (2):195-201. doi:10.1159/000357864

17. Pollesello P, Parissis J, Kivikko M, Harjola V-P. Levosimendan meta-analyses: is there a pattern in the effect on mortality? Int J Cardiol. 2016;209:77-83. doi:10.1016/j.ijcard.2016.02.014

18. Belletti A, Castro ML, Silvetti S, et al. The Effect of inotropes and vasopressors on mortality: a meta-analysis of randomized clinical trials. Br J Anaesth. 2015;115(5):656-675. doi:10.1093/bja/aev284

19. Sorsa T, Pollesello P, Rosevear PR, Drakenberg T, Kilpeläinen I. Stereoselective binding of levosimendan to cardiac troponin C causes Ca 2+-sensitization. Eur J Pharmacol. 2004. doi:10.1016/ j.ejphar.2003.12.006

20. Sorsa T, Heikkinen S, Abbott MB, et al. Binding of levosimendan, a calcium sensitizer, to cardiac troponin C. J Biol Chem. 2001;276 (12):9337-9343. doi:10.1074/jbc.M007484200

21. Mushtaq S, Andreini D, Farina S, et al. Levosimendan improves exercise performance in patients with advanced chronic heart failure. ESC Hear Fail. 2015. doi:10.1002/ehf2.12047

22. Nieminen MS, Fonseca C, Brito D, Wikström G. The potential of the inodilator levosimendan in maintaining quality of life in advanced heart failure. Eur Hear Journal, Suppl. 2017. doi:10.1093/eurheartj/ sux003

23. Pagel PS, Harkin CP, Hettrick DA, Warltier DC. Levosimendan (OR-1259), a myofilament calcium sensitizer, enhances myocardial contractility but does not alter isovolumic relaxation in conscious and anesthetized dogs. Anesthesiology. 1994;81(4):974-987. Available from: http://www.ncbi.nlm.nih.gov/pubmed/7943849. Accessed May 26, 2019.

24. Gruhn N, Nielsen-Kudsk JE, Theilgaard S, Bang L, Olesen SP, Aldershvile J. Coronary vasorelaxant effect of levosimendan, a new inodilator with calcium-sensitizing properties. $J$ Cardiovasc Pharmacol. 1998;31(5):741-749. Available from: http://www.ncbi. nlm.nih.gov/pubmed/9593074. Accessed February 20, 2019.

25. Erdei N, Papp Z, Pollesello P, Edes I, Bagi Z. The levosimendan metabolite OR-1896 elicits vasodilation by activating the K(ATP) and $\mathrm{BK}(\mathrm{Ca})$ channels in rat isolated arterioles. Br J Pharmacol. 2006;148 (5):696-702. doi:10.1038/sj.bjp.0706781

26. Höhn J, Pataricza J, Petri A, et al. Levosimendan interacts with potassium channel blockers in human saphenous veins. Basic Clin Pharmacol Toxicol. 2004;94(6):271-273. doi:10.1111/j.17427843.2004.pto940603.x

27. Hansen MS, Andersen A, Nielsen-Kudsk JE. Levosimendan in pulmonary hypertension and right heart failure. Pulm Circ. 2018. doi:10.1177/2045894018790905

28. Kersten JR, Montgomery MW, Pagel PS, Warltier DC. Levosimendan, a new positive inotropic drug, decreases myocardial infarct size via activation of K(ATP) channels. Anesth Analg. 2000;90 (1):5-11. Available from: http://www.ncbi.nlm.nih.gov/pubmed/ 10624967. Accessed February 20, 2019.

29. Maytin M, Colucci WS. Cardioprotection: a new paradigm in the management of acute heart failure syndromes. Am J Cardiol. 2005;96 (6A):26G-31G. doi:10.1016/j.amjcard.2005.07.018

30. Louhelainen M, Vahtola E, Kaheinen P, et al. Effects of levosimendan on cardiac remodeling and cardiomyocyte apoptosis in hypertensive Dahl/Rapp rats. Br J Pharmacol. 2007;150(7):851-861. doi:10.1038/ sj.bjp.0707157

31. Grossini E, Caimmi PP, Platini F, et al. Modulation of programmed forms of cell death by intracoronary levosimendan during regional myocardial ischemia in anesthetized pigs. Cardiovasc Drugs Ther 2010;24(1):5-15. doi:10.1007/s10557-010-6217-0
32. Caimmi PP, Molinari C, Uberti F, et al. Intracoronary levosimendan prevents myocardial ischemic damages and activates survival signaling through ATP-sensitive potassium channel and nitric oxide. Eur J Cardiothorac Surg. 2011;39(4):e59-e67. doi:10.1016/j.ejcts.2010.11.044

33. Onichimowski D, Nosek K, Goraj R, et al. Use of levosimendan in the treatment of cerebral vascular vasospasm: a case study. Drug Des Devel Ther. 2018. doi:10.2147/DDDT.S158237

34. Sandell EP, Hayha M, Antila S, et al. Pharmacokinetics of levosimendan in healthy volunteers and patients with congestive heart failure. J Cardiovasc Pharmacol. 1995; 26(Suppl 1):S57-S62. Available from: http:/www.ncbi.nlm.nih.gov/pubmed/8907132. Accessed February 20, 2019. doi:10.1097/00005344-199506261-00008

35. Kivikko M, Antila S, Eha J, Lehtonen L, Pentikäinen PJ. Pharmacokinetics of levosimendan and its metabolites during and after a $24 \mathrm{hr}$ continuous infusion in patients with severe heart failure. Int J Clin Pharmacol Ther. 2002;40(10):465-471. Available from: http://www.ncbi.nlm.nih.gov/pubmed/12395979. Accessed February 20, 2019.

36. Puttonen J, Kantele S, Ruck A, et al. Pharmacokinetics of intravenous levosimendan and its metabolites in subjects with hepatic impairment. J Clin Pharmacol. 2008;48(4):445-454. doi:10.1177/ 0091270007313390

37. Ishihara S, Gayat E, Sato N, et al. Similar hemodynamic decongestion with vasodilators and inotropes: systematic review, meta-analysis, and meta-regression of 35 studies on acute heart failure. Clin Res Cardiol. 2016;105(12):971-980. doi:10.1007/s00392-016-1009-6

38. Bouchez S, Fedele F, Giannakoulas G, et al. Levosimendan in acute and advanced heart failure: an expert perspective on posology and therapeutic application. Cardiovasc Drugs Ther. 2018. doi:10.1007/ s10557-018-6838-2

39. Packer M, Colucci W, Fisher L, et al. Effect of levosimendan on the short-term clinical course of patients with acutely decompensated heart failure. JACC Hear Fail. 2013;1(2):103-111. doi:10.1016/j. jchf.2012.12.004

40. de Lissovoy G, Fraeman K, Teerlink JR, et al. Hospital costs for treatment of acute heart failure: economic analysis of the REVIVE II study. Eur J Heal Econ. 2010;11(2):185-193. doi:10.1007/s10198009-0165-2

41. Moiseyev VS, Põder P, Andrejevs N, et al. Safety and efficacy of a novel calcium sensitizer, levosimendan, in patients with left ventricular failure due to an acute myocardial infarction. A randomized, placebo-controlled, double-blind study (RUSSLAN). Eur Heart J. 2002; 23(18):1422-1432. Available from: http://www.ncbi.nlm.nih. gov/pubmed/12208222. Accessed February 22, 2019. doi:10.1053/ euhj.2001.3158

42. Mebazaa A, Nieminen MS, Packer M, et al. Levosimendan vs dobutamine for patients with acute decompensated heart failure. JAMA. 2007;297(17):1883. doi:10.1001/jama.297.17.1883

43. Allou N, Allyn J, Bouchet B, et al. Impact of levosimendan on weaning from peripheral venoarterial extracorporeal membrane oxygenation in intensive care unit. Ann Intensive Care. 2019. doi:10.1186/s13613-019-0503-1

44. Farmakis D, Alvarez J, Ben GT, et al. Levosimendan beyond inotropy and acute heart failure: evidence of pleiotropic effects on the heart and other organs: an expert panel position paper. Int J Cardiol. 2016;222:303-312. doi:10.1016/j.ijcard.2016.07.202

45. Sangalli F, Avalli L, Laratta M, et al. Effects of levosimendan on endothelial function and hemodynamics during weaning from veno-arterial extracorporeal life support. $J$ Cardiothorac Vasc Anesth. 2016;30(6):1449-1453. doi:10.1053/j.jvca.2016.03.139

46. Crespo-Leiro MG, Metra M, Lund LH, et al. Advanced heart failure: a position statement of the Heart Failure Association of the European Society of Cardiology. Eur J Heart Fail. 2018. doi:10.1002/ejhf.1236 
47. Altenberger J, Parissis JT, Costard-Jaeckle A, et al. Efficacy and safety of the pulsed infusions of levosimendan in outpatients with advanced heart failure (LevoRep) study: a multicentre randomized trial. Eur J Heart Fail. 2014;16(8):898-906. doi:10.1002/ejhf.118

48. Comín-Colet J, Manito N, Segovia-Cubero J, et al. Efficacy and safety of intermittent intravenous outpatient administration of levosimendan in patients with advanced heart failure: the LION-HEART multicentre randomised trial. Eur J Heart Fail. 2018. doi:10.1002/ejhf.1145

49. García-González MJ, de Mora-Martín M, López-Fernández S, et al. Rationale and design of a randomized, double-blind, placebo controlled multicenter trial to study efficacy, security, and long term effects of intermittent repeated levosimendan administration in patients with advanced heart failure: LAICA study. Cardiovasc Drugs Ther. 2013;27(6):573-579. doi:10.1007/s10557-013-6476-7

50. Giannakoulas G, Harjola V-P, Oliva F, et al. Levosimendan in acute and advanced heart failure: an expert perspective on posology and therapeutic application. Cardiovasc Drugs Ther. 2018. doi:10.1007/ s10557-018-6838-2

51. Follath F, Cleland JGF, Just H, et al. Efficacy and safety of intravenous levosimendan compared with dobutamine in severe low-output heart failure (the LIDO study): a randomised double-blind trial. Lancet (London, England). 2002;360(9328):196-202. Available from: http:// www.ncbi.nlm.nih.gov/pubmed/12133653. Accessed February 22, 2019.

52. Yilmaz MB, Yalta K, Yontar C, et al. Levosimendan improves renal function in patients with acute decompensated heart failure: comparison with dobutamine. Cardiovasc Drugs Ther. 2007;21(6):431-435. doi: 10.1007/s10557-007-6066-7

53. Lannemyr L, Ricksten SE, Rundqvist B, et al. Differential effects of levosimendan and dobutamine on glomerular filtration rate in patients with heart failure and renal impairment: a randomized double-blind controlled trial. J Am Heart Assoc. 2018;7:16. doi:10.1161/ JAHA. 117.008455
54. Zemljic G, Bunc M, Yazdanbakhsh AP, Vrtovec B. Levosimendan improves renal function in patients with advanced chronic heart failure awaiting cardiac transplantation. J Card Fail. 2007;13 (6):417-421. doi:10.1016/j.cardfail.2007.03.005

55. Galiè N, Humbert M, Vachiery J-L, et al. ESC/ERS guidelines for the diagnosis and treatment of pulmonary hypertension. Eur Heart J. 2015;37(1):67-119. doi:10.1093/eurheartj/ehv317

56. Jiang R, Zhao Q-H, Wu W-H, et al. Efficacy and safety of a calcium sensitizer, levosimendan, in patients with right heart failure due to pulmonary hypertension. Clin Respir J. 2018;12(4):1518-1525. doi:10.1111/crj.12699

57. Martyniuk TV, Arkhipova OA, Kobal' EA, Danilov NM, Chazova IE. Possibilities of using levosimendan in patients with idiopathic pulmonary hypertension. Ter Arkh. 2012;84(9):83-88. Available from: http://www.ncbi.nlm.nih.gov/pubmed/23091860. Accessed February 22, 2019.

58. Poelzl G, Zwick RH, Grander W, et al. Safety and effectiveness of levosimendan in patients with predominant right heart failure. Herz. 2008;33(5):368-373. doi:10.1007/s00059-008-3051-2

59. Yilmaz MB, Yontar C, Erdem A, et al. Comparative effects of levosimendan and dobutamine on right ventricular function in patients with biventricular heart failure. Heart Vessels. 2009;24 (1):16-21. doi:10.1007/s00380-008-1077-2

60. Mishra A, Kumar B, Dutta V, Arya VK, Mishra AK. Comparative effect of levosimendan and milrinone in cardiac surgery patients with pulmonary hypertension and left ventricular dysfunction. J Cardiothorac Vasc Anesth. 2016;30(3):639-646. doi:10.1053/j. jvca.2016.01.015
Therapeutics and Clinical Risk Management

\section{Publish your work in this journal}

Therapeutics and Clinical Risk Management is an international, peerreviewed journal of clinical therapeutics and risk management, focusing on concise rapid reporting of clinical studies in all therapeutic areas, outcomes, safety, and programs for the effective, safe, and sustained use of medicines. This journal is indexed on PubMed Central, CAS,

\section{Dovepress}

EMBase, Scopus and the Elsevier Bibliographic databases. The manuscript management system is completely online and includes a very quick and fair peer-review system, which is all easy to use. Visit http://www.dovepress.com/testimonials.php to read real quotes from published authors. 